\title{
Jurassic bark
}

\author{
The subject of extinction and de-extinction are much in the news at the moment, but discussions tend to \\ focus on the loss or resurrection of charismatic animals like tigers or tyrannosaurs. Where is the talk of \\ the plant species that have been lost and that might be worth bringing back?
}

Last month saw Jurassic World break box office records across the globe. Like the previous three films in the franchise it wonders what it would be like for humans to walk with dinosaurs. This is no new idea in fiction dating back to Arthur Conan Doyle and Jules Verne, but serious scientific attempts are now being made to bring back species from beyond extinction.

In 2009 scientists used cloning to produce an individual of an extinct species, the Pyrenean ibex. The procedure used tissue cultures originating from the last surviving individual prior to its death in 2000 (a far cry from mosquitoes preserved in amber) and the clone only lived for seven minutes due to a lung defect, but a precedent has been set. Other research projects are attempting to recreate animals such as the quagga (a subspecies of zebra) and the auroch cattle of Pleistocene Europe by selective breeding from modern relatives. Genome editing has been proposed for re-engineering woolly mammoths or reintroducing dinosaurian characteristics into modern birds. In all this there is no talk of recreating the flora of ancient times. Is this simply an example of antiplant discrimination or is there some other reason?

Species go extinct and new ones emerge all the time. However, there have been at least five global mass extinctions in the history of life on Earth, short periods when large numbers of species, genera and even larger groupings cease to exist. The most recent occurred at the end of the Cretaceous period some 66 million years ago $(\mathrm{Ma})$, triggered by an asteroid hitting the earth somewhere off the coast of Mexico, which resulted in the loss of three quarters of animal species. We may currently be in the middle of a sixth mass extinction driven by our own activities. For example, a paper by G. Ceballos et al. last month (Sci. Adv. 1, e1400253; 2015) estimated that the rate of species extinction over the last century was up to 114 times higher than the expected background rate.

Research into mass extinction events tends to concentrate on animal species and particularly vertebrates, which leave the best fossils. However, earlier this year a study from Daniele Silvestro and colleagues specifically looked at the effect of the great mass extinction events on plants (New Phytol. 207, 425-436; 2015). This analysis used Bayesian statistics to estimate extinction and speciation events in plants based on the known fossil record. They found that plant species have been far less affected by these major global events.

Plants did suffer increased rates of extinction at these times of considerable environmental change, but the losses were less dramatic than seen for animals and plant net speciation recovered more quickly. In fact the data for plants alone identified just three mass extinctions echoing an earlier study by B. Borja Cascales-Miñana, B. \& C. J. Cleal (Terra Nova 26, 195-200; 2014) that saw only two mass extinctions of plants. One consequence of this may be that losses of whole classes of plant are rare, making living relatives of extinct plant species more common than for animal groups.

However, a multitude of plant species have been lost. Which would make good candidates for resurrection? For the spectacle alone Araucaria mirabilis would be a contender. These pine trees grew in the Jurassic period and are preserved in great numbers in Cerro Cuadrado Petrified Forest, Patagonia. They grew up to $100 \mathrm{~m}$ tall and had cones almost $10 \mathrm{~cm}$ in length.

Or how about Aglaophyton major, which lived in the Devonian era (around $410 \mathrm{Ma}$ ) and is found as fossils in the Rhynie chert deposits in Aberdeenshire, Scotland? It was a plant right at the cusp of developing a true vascular system and was among the first to associate with mycorrhizal fungi. A. major is a relative of modern club mosses as are the Lepidodendron or scale trees. These lived in the Carboniferous period (360 Ma) and had trunks covered not with bark but with soft scaly tissue, sometimes mistaken for the skin of some giant fossil snake.

As the Jurassic World theme park is sited on an island (Isla Nuba about 120 miles off the coast of Costa Rica) it might be sensible to reengineer a whole island flora, say that of Easter Island (Rapa Nui), and with it the majestic palm, Paschalococos disperta. This may have grown to $15 \mathrm{~m}$ tall and so been the tallest palm alive at that time but we now only know of it from archaeological samples of discarded nut cases and pollen preserved in lake beds. It was the arrival of humans between 700 and 1100 , or the rats that came with them, that sounded the death knell for the island's forests.

Another plant worth resurrecting would be silphium, used in and around the Mediterranean until the third or second century вС. This herb was used in cooking, as a medicine for all kinds of aches and pains and also as a contraceptive. The great demand for the plant in the ancient world - the Romans valued it as worth its weight in silver coins - drove it to extinction by overconsumption. Resurrecting silphium would be particularly difficult, however, as no samples of it remain and there is no consensus on its precise identity.

Or wouldn't it be fun to have examples of the tulips that were at the heart of the economic turmoils in Holland in the 1600s? At that time, tulips were a highly prized commodity and uncontrolled speculation drove prices up to untenable levels before the bubble burst and they abruptly crashed. At the height of 'tulip madness' a bulb of the variety Semper augustus was traded for 12 acres of land and that of Viceroy for the equivalent of sixteen times the annual wage of a skilled labourer. Illustrations of those flowers are all that remain.

The idea of using genetic engineering to de-extinct lost species may sound farfetched and there are substantial barriers to overcome before we will see live examples of Tasmanian tigers or dodos. But the exact same approaches being applied to those projects are available in plant biology and the techniques of plant breeding, such as the generation of individuals from calli, may make it easier for budding phytoresurrectionists to exhume their extinct species of choice.

Of course the genetic engineers in Jurassic World do not confine themselves to dinosaurs that once lived, but begin to create whole new species: bigger, scarier and with more teeth. So perhaps we should consider making a Triffid; an excellent source of biofuel oil whose venom has impressive pharmacological potential. 